\section{The Canadian Association of Gastroenterology Education Committee Report}

Ronald J Bridges MD FRCPC

Chair, CAG Education Committee

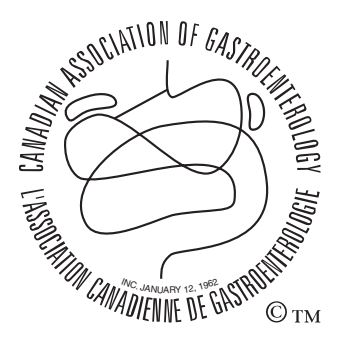

En français voir page 635
I

Tam pleased to provide an update regarding the activities and uture directions of the Canadian Association of Gastroenterology (CAG) Education Committee. The mandate of the CAG Education Committee is to facilitate, develop and promote excellence as it pertains to educational initiatives for the Canadian gastroenterology community. Professional education has long remained a priority of the $\mathrm{CAG}$ - a fact well recognized by the membership. The 2002 CAG Strategic Planning Survey showed that members rate Canadian Digestive Diseases Week (CDDW) as the most important CAG service, on par with Digestive Diseases Week regarding its usefulness (1). CDDW 2004 offered delegates a variety of basic science and clinical symposia, the popular and well received 'Breakfast with the Expert' sessions and a comprehensive Postgraduate Course reviewing key developments in gastroenterology, nutrition and hepatology.

At CDDW 2004, the Education Excellence Award was presented to Dr Ivan Beck in recognition of his dedicated lifelong efforts to the mentoring of gastroenterology trainees. He is a staunch advocate of young investigators and has served as a mentor to many Canadian trainees. I am pleased to announce the development of a new award: the CAG Young Educators Award. This award will be presented annually to a young Canadian gastroenterologist who shows a commitment to the advancement of education in the fields of gastroenterology, nutrition and/or hepatology.

In addition to contributing to the implementation of CDDW, the multiple and varied activities of the CAG Education Committee are actively managed by several subcommittees:

\section{Maintenance of Certification Subcommittee}

As you know, the CAG applied for, and was granted, national accreditor status on behalf of the Royal College of Physicians and Surgeons of Canada (RCPSC) during 2003. The role of the Maintenance of Certification Subcommittee, chaired by Dr Connie Switzer, is to review educational programs on behalf of the CAG in accordance with RCPSC guidelines. Applications for accreditation of events may be submitted by physicians or industry and are reviewed and addressed by the committee within two to four weeks. In 2003, 13 programs were evaluated, of which 12 were approved for a total of $76 \mathrm{~h}$ of Category 1 (group learning activity) credit. Dr Switzer will provide a more detailed description regarding the CAG and Maintenance of Certification in an upcoming edition of the CAG News page.

\section{Gastroenterology Residents in Training Course} Subcommittee

Established in 1992, the highly successful Gastroenterology Residents in Training (GRIT) course - now sponsored by the Fairmont Banff Springs - has become an annual event held in conjunction with CDDW. The aim of the course is to provide up to 80 competitively selected Canadian adult and pediatric trainees in gastroenterology with an opportunity to present their work and expand their knowledge of selected topics in gastroenterology, nutrition and hepatology in a context that allows critical evaluation, while interacting closely with a small number of recognized, effective Canadian teachers. The impact of the GRIT course has transcended borders: the organizers of the American Gastroenterology Fellows Course have used our GRIT course as a model. Many GRIT graduates have gone on to prominent positions at medical schools throughout North America. Currently co-chaired by Drs David Armstrong and Nicola Jones, the course represents a significant investment in gastroenterology trainee education, costing approximately $\$ 2,200$ per attendee. The 2004 recipient of the GRIT Course Ivan T Beck Lectureship, awarded annually in honour of Dr Ivan Beck to a distinguished clinician-scientist and educator, was Dr J Richard Hamilton.

\section{Scholars Program Subcommittee}

In the long term, we must continue to attract bright and enthusiastic trainees to the field of gastroenterology. To this end, the Scholars Program was started in 2001 to encourage third and fourth year medical students, and first and second year internal medicine and pediatric residents, to consider a subspecialty career in gastroenterology. Currently co-chaired
Abbott Laboratories Ltd.
AstraZeneca Canada Inc.
Axcan Pharma Inc.
Janssen-Ortho Inc.
Pfizer Canada Inc. 
by Drs Jamie Gregor and Clarence Wong and co-sponsored by ALTANA Pharma Inc and Solvay Pharma Inc, the Scholars Program is held each year in conjunction with the CDDW. Participants are provided a view of the various careers that are possible in gastroenterology including basic science research, clinical research, medical education and community gastroenterology. The program also reviews ethical challenges in medicine, advances in gastroenterology and what it is like to be a gastroenterology fellow. Participants have the opportunity to interact in small groups and to test their skills with an endoscopy challenge. The two-day intensive program allows students the chance to work with and learn from an internationally recognized academic and clinical faculty who are respected leaders and role models in the field.

The Scholars Program is highly competitive: of the approximately 160 eligible candidates across the country, a maximum of 32 participants (one to three from each medical school) are invited to attend. Feedback has been extremely positive, and would suggest that the program has helped to entice residents to a residency in gastroenterology. Since its inception, the program has produced 120 'graduates'.

\section{Residents Videoconference Subcommittee}

The residents' videoconference was developed in 2002 in response to a perceived difficulty in running basic and clinical science rounds of sufficient breadth and depth as part of gastroenterology training programs across the country. With the sponsorship of AstraZeneca Canada Inc and under the guidance of co-chairs Drs Janice Barkey and Dana Farina, recognized international experts from various centres of excellence conduct a monthly videoconference. Support by university videoconference sites and attendance for sessions has been excellent, with feedback provided from residents being extremely positive.

\section{Interactive Lecture Series Subcommittee}

The CAG Interactive Lecture Series, chaired by Dr Richard Fedorak, is a highly innovative, web-based virtual learning opportunity that permits physicians to see, hear and review lectures, workshops and symposia presented by internationally renowned experts. It is an outstanding program that easily extends access to continuing medical educational opportunities. The Lecture Series is regularly updated and is available free of charge on the CAG Web site. There are currently over 130 presentations available through this program.

\section{Program Directors Subcommittee}

Dr Bill Depew currently chairs the RCPSC Program Directors Committee. It provides CAG with information regarding the development of objectives, curriculum, accreditation standards and guidelines for Canadian Gastroenterology Training Programs.

\section{FUTURE DIRECTIONS}

We need to continue to proceed carefully and thoughtfully with the development of future educational initiatives to meet the needs of the membership because financial and human resources of CAG are required. Members have a vested interest in ensuring the continued success of CAG. I believe we can continue to provide a high standard of programming. A pressing problem is the need to improve the acquisition of feedback from the membership regarding their educational needs. The recently completed 2004 CAG Educational Needs Assessment resulted in a disappointing membership response rate of $7.4 \%$. This provides limited data for the development of future initiatives. One of the obstacles to program development is the perception of a complex process of needs analysis. This perception may have contributed to the poor response rate on the recent CAG needs assessment. Increasing time demands on gastroenterologists make the completion of surveys difficult and tedious. However, a needs assessment is a critical component of developing independent educational programs. CAG has tried to minimize the time involved for completion of the annual needs assessment by creating a simple check box survey on the CAG Web site. In reality, the completion of a needs analysis takes only a few minutes and plays a crucial role in the development of future educational endeavours.

An example of an innovative new program sponsored by the CAG is the Practice Audit in Gastroenterology (PAGE) program. The PAGE program is a groundbreaking approach to continuing professional development; specifically, practice audits. Physicians are lent preprogrammed personal digital assistants on which they record data for a specified time period. At the conclusion of the audit, data are downloaded to a laptop computer and e-mailed to a central server and database. Via password protection, physicians can review their individual results and the aggregate data of all participants. PAGE removes the burden of developing an audit protocol, eliminates paperwork and offers the benefits of real-time collection and review of data from many participants, all while earning Category 5 RCPSC credits.

PAGE-Endoscopy and PAGE-Colonoscopy involved recording details of upper gastrointestinal endoscopies or colonoscopies performed over a three-week period. Responses from participants of both programs were extremely positive, with the vast majority rating PAGE as easy to use and beneficial. The newest program, PAGE - A Week in the Life of a Gastroenterologist, takes a different approach by having specialists record time spent on various professional activities (clinical work, administration, research and teaching) for a one-week period. The intent of PAGE-Week in the Life is to obtain manpower data on gastroenterology in Canada, as a foundation for CAG advocacy initiatives. Physicians interested in taking part in PAGE are encouraged to visit the CAG Web site under Education for further details and a sign-up form.

I trust you are by now aware of the World Congress of Gastroenterology 2005 in Montreal, Quebec, September 10 to 13, 2005. In addition to the excellent World Congress of Gastroenterology educational events, the CAG will run a short separate program suitable for clinicians, scientists and trainees. I strongly encourage you to register now and attend.

The recently completed CAG 2004 five year Strategic Plan outlined several goals for the CAG Education Committee (2). Educational initiatives in the plan include: enhancing the scope of existing programs; promoting and facilitating, with appropriate partners, regional educational programs for the practicing community gastroenterologist; establishing leadership and 
teaching skill development programs; creating and disseminating practice guidelines and technical reviews; and utilizing technological advancements in the provision of future educational initiatives.

I am honoured to serve as the Chair of the CAG Education Committee and very much welcome your comments and feedback regarding the role of the Committee in meeting your needs. Challenges remain and we need to meet them. Many are amenable to correction with your active participation in the organization. The continued development of innovative, high quality educational endeavours requires your participation, feedback and active support. Suggestions can be forwarded to me, any member of the Education Committee, or the National Office at CAGoffice@cag-acg.org. The Education Committee endeavours to continue the existing high quality programs and enter a new era of innovative educational initiatives to meet the needs of the clinician, basic scientist, clinical investigator and trainee.

ACKNOWLEDGEMENTS: I gratefully acknowledge the efforts of the members of the Education Committee (Janice Barkey, John Fardy, Dana Farina, Marty Fishman, Jamie Gregor, Terrence Moore, Alaa Rostom, Richard Schreiber and Connie Switzer) and subcommittees (David Armstrong, Kelly Burak, Nicola Jones, Josee Parent, Alan Thomson and Clarence Wong), Mr Paul Sinclair, the CAG National Executive Director and Ms Sandra Daniels, Manager, CAG.

\section{REFERENCES}

1. Sherman P, Daniels S, Fedorak R. Summary of the 2002 CAG strategic planning survey. Can J Gastroenterol 2004;18:55-6.

2. Sherman P, Fedorak R, Leddin D, Wallace J. Canadian Association of Gastroenterology 2004 Strategic Plan. Can J Gastroenterol 18:125-6. 


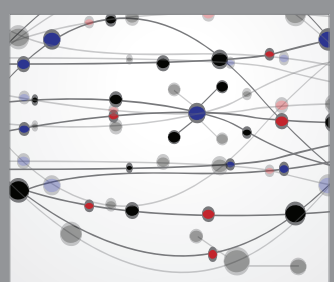

The Scientific World Journal
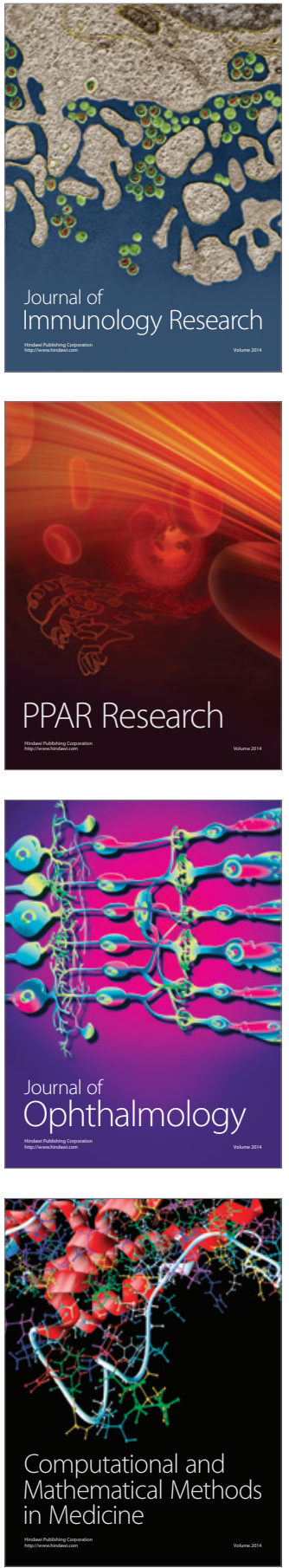

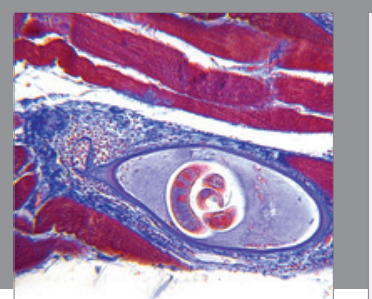

Gastroenterology Research and Practice

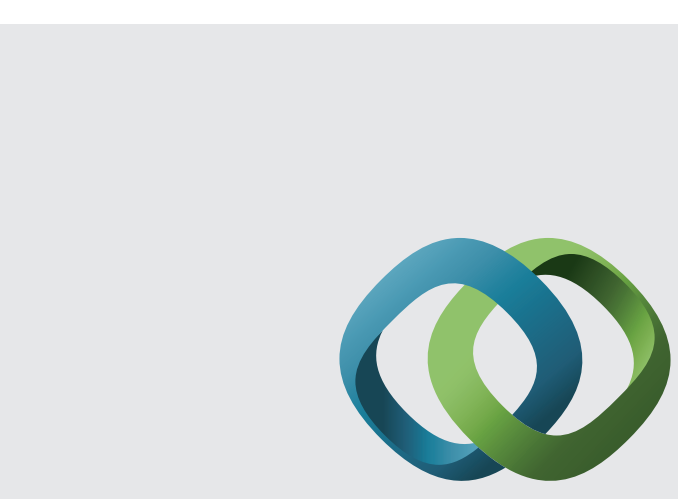

\section{Hindawi}

Submit your manuscripts at

http://www.hindawi.com
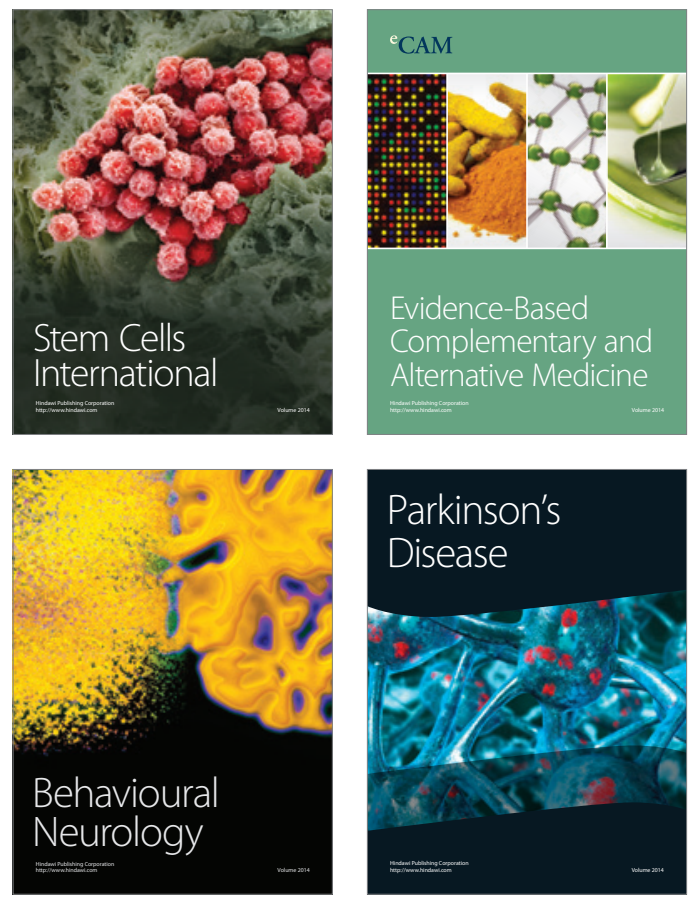
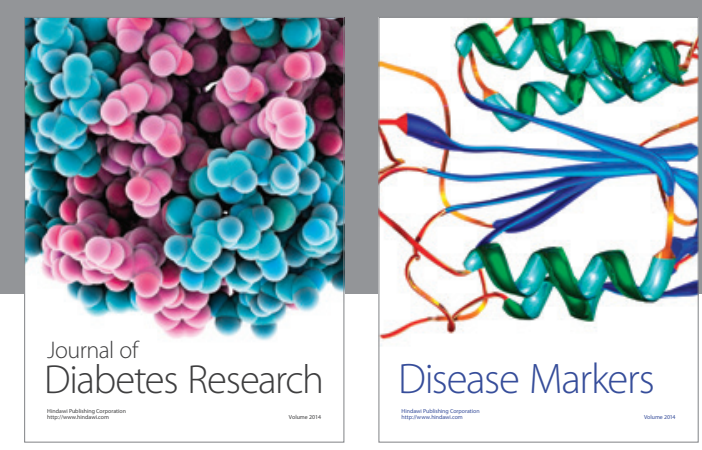

Disease Markers
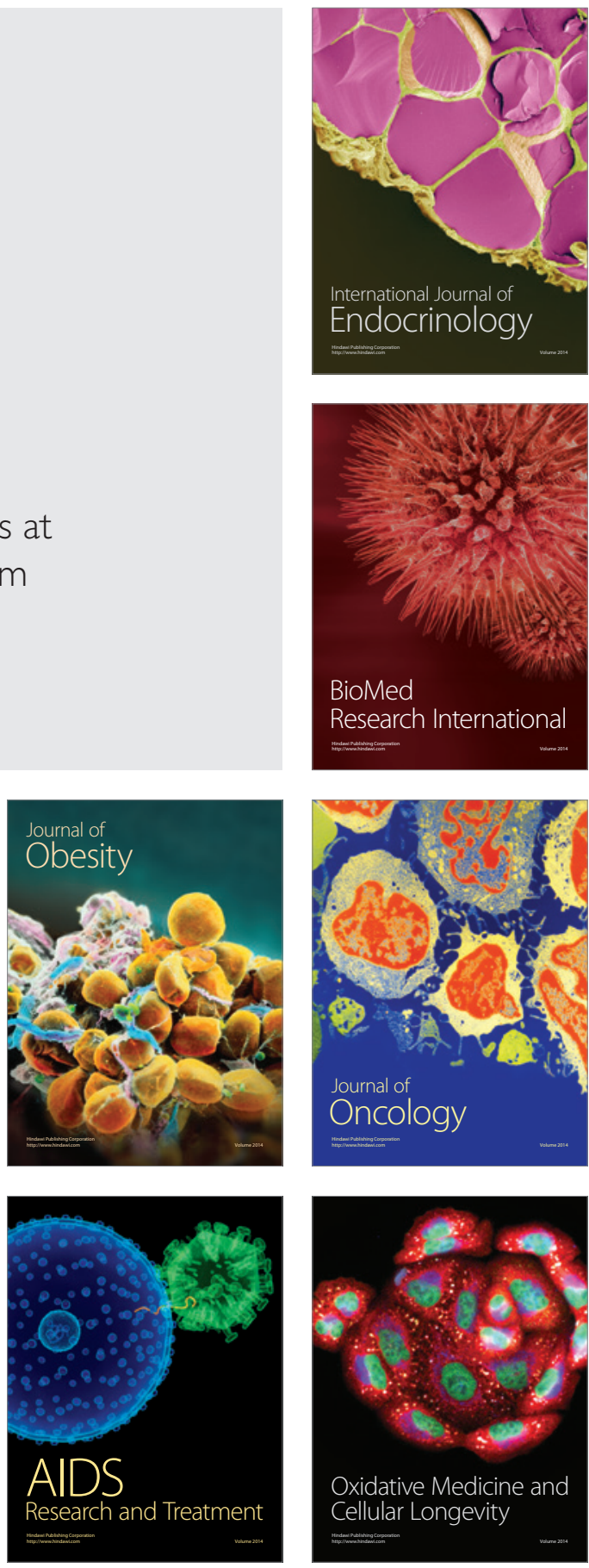